\title{
Comparing the Efficacy of DeVIC Therapy and High-dose Methotrexate Monotherapy with Whole-brain Radiation Therapy for Newly-diagnosed Primary Central Nervous System Lymphoma: A Single Institution Study
}

\author{
LUSHUN CHALISE, KAZUYA MOTOMURA, FUMIHARU OHKA, MASAKI HIRANO, \\ MASAHITO HARA, YUSUKE NISHIMURA, ATSUSHI NATSUME and TOSHIHIKO WAKABAYASHI \\ Department of Neurosurgery, Nagoya University School of Medicine, Nagoya, Japan
}

\begin{abstract}
Background/Aim: In the current study, we aimed to compare DeVIC (dexamethasone, etoposide, ifosfamide and carboplatin) chemotherapy with high-dose methotrexate (HD-MTX) monotherapy plus whole-brain radiation therapy (WBRT) for newly-diagnosed primary central nervous system lymphoma (PCNSL), in terms of their efficacies and tolerability. Patients and Methods: A total of 21 consecutive patients with PCNSL were treated with DeVIC therapy and WBRT, between 2002 and 2010. From 2010 to 2014, 14 consecutive patients with PCNSL were treated with HD-MTX followed by WBRT. Results: Overall response rates of complete and partial response for initial chemotherapy were significantly better with DeVIC therapy (95.2\%) than with HD-MTX monotherapy (50\%). Furthermore, one-year and two-year progression-free survival (PFS) rates were better in the DeVIC cohort than in the HD-MTX cohort. DeVIC therapy yielded higher early response rates, longer PFS, and manageable adverse events, and may be potentially better for the treatment of cases that are refractory to MTX-based therapy. Conclusion: Our retrospective clinical study revealed that DeVIC therapy is comparable with that of $H D$ MTX monotherapy plus WBRT, for newly diagnosed PCNSL.
\end{abstract}

The treatment of primary central nervous system malignant lymphomas (PCNSL) has changed over the past few decades from radiation-based therapy to various regimens of chemotherapy. In the past, whole-brain radiation therapy (WBRT) has allowed the achievement of a prolonged median

Correspondence to: Dr. Kazuya Motomura, Department of Neurosurgery, Nagoya University School of Medicine, 65 Tsurumaicho, Showa-ku, Nagoya 466-8550, Japan. Tel: +81 527442353, Fax: +81527442360, e-mail: kmotomura@med.nagoya-u.ac.jp

Key Words: Primary central nervous system lymphoma (PCNSL), DeVIC therapy, HD-MTX therapy. overall survival (OS) time of 11.6 months to PCNSL patients (1). The addition of therapy with high-dose methotrexate (HD-MTX) to WBRT was associated with significantly improved patient outcomes with the median OS ranging from 32.4 to 55.4 months (2-6), and various HD-MTX-based regimens (with or without radiation therapy) have been assessed with overall favorable results (2-7). Thus, HDMTX-based chemotherapy has been widely used henceforth as the standard treatment modality with moderate outcomes $(8,9)$. However, the outcomes of several randomized clinical trials have not revealed a clear advantage for the use of HDMTX $(4,10)$. Furthermore, the combination of MTX and radiation is significantly associated with treatment-related neurotoxicity (11-14).

Recent clinical trials have shown that high-dose chemotherapy could replace radiotherapy owing to the longer survivals and manageable adverse events associated with the former (15-17). Moreover, recent developments have shown better prognoses with strong systemic chemotherapy, especially with HD-MTX- and rituximab-based multi-drug regimens $(16,17)$. Therapy with HD-MTX remains the mainstay treatment for PCNSL; however, the choice of optimal therapy for the patients who are refractory to the standard regimen has not been defined. Thus, a standard second-line treatment for patients with PCNSL relapsed or refractory to HD-MTX-based chemotherapy should be established.

In our institution, we treat patients with PCNSL using a combination of chemotherapy and WBRT. We have altered our chemotherapy regimen and the total dose of WBRT accordingly, with an aim of reducing the total irradiation, wherever possible. We have previously reported our results with 21 consecutive cases of newly diagnosed PCNSL treated with DeVIC therapy (18). Here, we report our results with 14 consecutive cases of newly diagnosed PCNSL treated with HD-MTX therapy, and compared the outcomes of this study with those of DeVIC therapy in our previous study. This 
retrospective study was undertaken to compare DeVIC therapy with HD-MTX regimen in terms of response rates, survival and treatment toxicity in patients with newly diagnosed PCNSL.

\section{Materials and Methods}

Characteristics of patients. In this retrospective study, we analyzed all patients with newly-diagnosed PCNSL who had undergone initial therapy at the Nagoya University hospital, between January 2002 and December 2013. We have previously reported the results of DeVIC chemotherapy and WBRT in 21 cases of newly diagnosed PCNSL (18). We collected data for 14 consecutive patients with newly diagnosed PCNSL who were treated with HD-MTX monotherapy plus WBRT from October 2010 to December 2013.

According to guidelines established by the World Health Organization (WHO) (19), all patients were immunocompetent, and had been diagnosed with malignant lymphomas by at least two independent neuropathologists, using the tissue samples obtained via tumor resections or needle biopsies. Patients who had previously been diagnosed with intraocular malignant lymphomas at our institution were waived off a second biopsy for any intracranial lesions that were radiologically diagnosed as malignant lymphomas. All patients retained adequate functioning of major organs at the start of treatment; this was verified by investigating the white blood cell counts $(3,000$ cells $/ \mu \mathrm{l})$, absolute neutrophil counts $(1,200$ cells $/ \mu \mathrm{l})$, platelet counts $(100,000$ cells $/ \mu \mathrm{l})$, total serum bilirubin $(2.0$ $\mathrm{mg} / \mathrm{dl})$, and levels of aspartate and alanine aminotransferases (5 times the upper limit of normal level).

None of the patients had other symptomatic central nervous system lesions, co-occurring cancers, severe infectious diseases, or severe chronic disorders. Baseline pre-treatment evaluations included neurological and physical examinations; contrast-enhanced cranial magnetic resonance imaging (MRI); ophthalmologic examinations, including slit-lamp evaluations and F-18 fluoro-2deoxyglucose positron emission tomography (FDG-PET); and computed tomography (CT) of the chest, abdomen, and pelvis. None of the patients had positive human immunodeficiency virus (HIV) serology or evidence of systemic lymphomas. However, bone marrow biopsies and lumbar punctures to test cerebrospinal fluid were not performed routinely.

Karnofsky performance scale (KPS) scores were assigned by the clinicians at the time of evaluation of patients' neurological findings. This study was approved by the institutional review board at the Nagoya University Hospital (approval number: 2016-0134), and complied with all the provisions of the Declaration of Helsinki.

Treatment regimen. The patients were treated according to the institutional protocol of the Nagoya University School of Medicine, Japan. As previously reported, in our institution, the DeVIC regimen was the standard chemotherapy for newly diagnosed PCNSL, from 2002 to 2010 (18). Briefly, the DeVIC protocol included chemotherapy with dexamethasone, etoposide, ifosfamide, and carboplatin, followed by WBRT of $40 \mathrm{~Gy}$, with or without a local boost of $20 \mathrm{~Gy}$ (Figure 1). The treatment protocol for patients with PCNSL that was newly diagnosed between 2010 and 2015 consisted of systemic intravenous HD-MTX chemotherapy followed by a WBRT of 40 Gy. Although our DeVIC regimen was promising for PCNSL, HD-MTX chemotherapy was commonly being used as the first line standard treatment therapy for PCNSL in Japan by 2010; therefore, we changed our first line therapy for PCNSL to HD-MTX to compare the results to our results with DeVIC therapy. A high dose of MTX $\left(3.5 \mathrm{~g} / \mathrm{m}^{2}\right)$ was administered to the patients every 2 weeks for up to 5 cycles, before they received WBRT of $40 \mathrm{~Gy}$ in 20 fractions. None of the patients received local radiation boosts (Figure 1).

Leukocytopenia and neutropenia (leukocyte counts below $1,000 / \mu 1$ or absolute neutrophil counts below $500 / \mu \mathrm{L}$ ) were treated with granulocyte colony-stimulating factor, which was discontinued if the leukocyte counts increased to $5,000 / \mu 1$. In patients with other adverse events of grade 3 or more, the next cycles of chemotherapy were delayed until the systemic conditions of the patients recovered.

Evaluation of treatment response and toxicity. Responses were assessed by evaluating tumor sizes imaged by contrast-enhanced MRI scans. The responses were assessed 7 to 14 days after completion of chemotherapy and within 7 days of completion of radiation therapy, according to the International Primary CNS Lymphoma Study Group (IPCG) criteria (20). The timing of the evaluation of initial and overall responses was revealed in DeVIC and HD-MTX chemotherapy protocol regimens (Figure 1). Per the response evaluation criteria in solid tumors (RECIST) (20), individual responses were classified according to the standard radiographic criteria as complete response (CR), partial response (PR), stable disease (SD), or progressive disease (PD), as previously described (18).

Treatment failure was defined as experiencing PD or SD, relapse after the initial response, death, or discontinuation of chemotherapy, regardless of the cause. Relapse or progression was defined as tumor growth or regrowth as observed in the MRI scans. Acute adverse events, including both hematologic and non-hematologic toxicity, were graded according to the Common Terminology Criteria for Adverse Events (CTCAE) v4.0 (21).

Delayed neurotoxicity. Routine MRIs were obtained for all patients who had survived their initial therapy. The most recent MRIs were evaluated for the presence of brain atrophy and leukoencephalopathy. All patients underwent complete neurological examinations; in addition, data regarding their impaired concentration, memory, and orientation; the presence of ataxia and incontinence; the need for help; and fitness for work were obtained from all patients or their caregivers, in order to investigate and evaluate any delayed neurotoxicity.

Statistical analysis. OS and progression-free survival (PFS) were estimated by the Kaplan-Meier method. OS was calculated from the date of diagnosis by biopsy to the date of death or of last followup. PFS was calculated from the first date of initial chemotherapy to the first date of disease progression. The Mann-Whitney $U$-test, Student's $t$-test, $\chi^{2}$ test, and Fisher's exact test were used to test for the association of clinical variables between DeVIC and HD-MTX therapy groups. Statistical analyses were performed using the statistical software $\mathrm{R}$ version 3.2.2 and IBM SPSS Statistics for Windows, version 24.0 (IBM Corporation, Armonk, NY).

\section{Results}

Patient characteristics. From January 2002 to September 2010, 21 consecutive patients with PCNSL underwent DeVIC chemotherapy and WBRT at our institution, as previously described (18). On the other hand, between October 2010 and January 2014, 14 patients diagnosed with PCNSL underwent 
Table I. Clinical characteristics and outcomes of patients treated with DeVIC and HD-MTX therapy.

\begin{tabular}{|c|c|c|c|c|c|}
\hline \multirow[b]{2}{*}{ Parameter } & \multicolumn{2}{|l|}{ DeVIC } & \multicolumn{3}{|l|}{ HD-MTX } \\
\hline & $\begin{array}{l}\text { No. of } \\
\text { patients } \\
(n=21)\end{array}$ & $(\%)$ & $\begin{array}{l}\text { No. of } \\
\text { patients } \\
(\mathrm{n}=14)\end{array}$ & $(\%)$ & $p^{*}$ \\
\hline \multicolumn{6}{|c|}{ Age (years) } \\
\hline Median & 60.5 & & 67 & & 0.07 \\
\hline Range & $19-79$ & & $49-78$ & & \\
\hline \multicolumn{6}{|l|}{ Age, Years } \\
\hline$<60$ & 8 & 38.1 & 1 & 7.1 & $0.04 *$ \\
\hline$\geq 60$ & 13 & 61.9 & 13 & 92.9 & \\
\hline \multicolumn{6}{|l|}{ Gender } \\
\hline Male & 15 & 71.4 & 7 & 50.0 & 0.199 \\
\hline Female & 6 & 28.6 & 7 & 50.0 & \\
\hline \multicolumn{6}{|l|}{ Initial KPS } \\
\hline Median & 80 & & 90 & & 0.07 \\
\hline Range & $40-100$ & & $60-100$ & & \\
\hline \multicolumn{6}{|l|}{ Initial KPS } \\
\hline$<70$ & 10 & 47.6 & 2 & 14.3 & $0.042^{*}$ \\
\hline$\geq 70$ & 11 & 52.4 & 12 & 85.7 & \\
\hline \multicolumn{6}{|c|}{$\begin{array}{l}\text { Response to initial } \\
\text { chemotherapy }\end{array}$} \\
\hline $\mathrm{CR}$ & 13 & 61.9 & 3 & 21.4 & $0.019^{*}$ \\
\hline PR & 7 & 33.3 & 4 & 28.6 & 0.669 \\
\hline $\mathrm{SD} / \mathrm{PD}$ & 1 & 4.8 & 7 & 50.0 & $0.002 *$ \\
\hline \multicolumn{6}{|c|}{$\begin{array}{l}\text { Response to } \\
\text { chemotherapy/RT }\end{array}$} \\
\hline CR & 17 & 80.9 & 9 & 64.3 & 0.269 \\
\hline PR & 3 & 14.3 & 2 & 14.3 & 1 \\
\hline $\mathrm{SD} / \mathrm{PR}$ & 1 & 4.8 & 3 & 21.4 & 0.129 \\
\hline
\end{tabular}

KPS: Karnofsky performance status; CR: complete response; PR: partial response; SD: stable disease; PD: progressive disease; RT: radiation therapy; DeVIC: dexamethasone, etoposide, ifosfamide and carboplatin; HD-MTX: high dose methotrexate. * $p$-Values calculated by Fisher's exact test. $p<0.05$ was considered statistically significant.

HD-MTX chemotherapy followed by WBRT. The main baseline clinical characteristics and treatment outcomes of the DeVIC- and HD-MTX-treated cases are summarized in Table I. Median ages at diagnoses were 60.5 and 67 years in the DeVIC and HD-MTX groups, respectively. The DeVIC and HD-MTX therapy groups had $71.4 \%$ and $50 \%$ male patients, respectively. Furthermore, initial KPS scores were good in both groups with a median of 80 in the DeVIC group and 90 in the HD-MTX group. A KPS score of 70 or more was found in $52.4 \%$ patients of the DeVIC cohort and in $85.7 \%$ patients of the HD-MTX cohort. All patients received chemotherapy and subsequent WBRT with 40 Gy of radiation.

Response rate and survival of DeVIC chemotherapy and $H D-M T X$ therapy. After initial chemotherapy, CR was
Table II. Survival data for DeVIC vs. HD-MTX treatment.

\begin{tabular}{lccc}
\hline & Median & $95 \% \mathrm{CI}$ & $p$-Value \\
\hline OS (months) & & & \\
DeVIC & 47.8 & $11.4-84.1$ & 0.435 \\
HD-MTX & $\mathrm{NR}$ & $\mathrm{NR}$ & \\
PFS (months) & & & \\
DeVIC & 37.4 & $7.0-67.7$ & 0.672 \\
HD-MTX & 25.3 & $\mathrm{NR}$ & \\
\hline
\end{tabular}

OS: Overall survival; PFS: progression free survival; CI: confidence interval; DeVIC: dexamethasone, etoposide, ifosfamide and carboplatin; HD-MTX: high-dose methotrexate; NR: not reached.

identified in 13 of $21(61.9 \%)$ patients in the DeVIC group, and in 3 of $14(21.4 \%)$ patients in the HD-MTX group $(p=0.019)$. Overall response rates of CR and PR for initial chemotherapy were better with DeVIC therapy (95.2\%) than with HD-MTX therapy $(50 \%)(p=0.002)$. Furthermore, after addition of radiation therapy to the initial chemotherapy, CR was achieved in 17 (80.9\%) and 9 (64.3\%) patients in the DeVIC and HD-MTX groups, respectively $(p=0.269)$. The overall response rates were 95.2\% in the DeVIC group and $78.6 \%$ in the HD-MTX group ( $p=0.129)$ (Table I). The 8 patients in the non-CR group of the DeVIC cohort were immediately treated with adjuvant radiotherapy either during or after the chemotherapy. Six patients in the HD-MTX cohort received radiation therapy before the completion of 5 rounds of HDMTX because tumor regrowth was found in these patients. Eight patients completed 5 cycles of HD-MTX and subsequently underwent WBRT. These 8 patients achieved CRs at the time of completion of WBRT.

Median OS for patients treated with DeVIC therapy was 47.8 months (95\% CI=11.4-84.1 months) after an average observation period of 24.9 months, whereas median OS had not been reached for HD-MTX cohort $(95 \% \mathrm{CI}=\mathrm{NA})$ $(p=0.435$; Figure 2A; Table II) after an average observation period of 24.3 months. Median PFS was 37.4 months (95\% CI=7.0-67.7 months) in the DeVIC cohort compared to 25.3 months $(95 \% \mathrm{CI}=\mathrm{NA})$ in the HD-MTX cohort $(p=0.672$; Figure 2B; Table II). No significant differences were observed in PFS of both DeVIC and HD-MTX cohorts.

Furthermore, one-year and two-year PFS rates were higher in the DeVIC cohort than in the HD-MTX cohort. The twelve month-PFS rates were $68.1 \%$ and $61.5 \%$ for the DeVIC and HD-MTX cohorts, respectively. The twenty-four month-PFS rates were $62.4 \%$ and $55.6 \%$, respectively, for the DeVIC and HD-MTX groups. This difference was not statistically significant, as determined by the log-rank test and univariate analyses (Table III). 


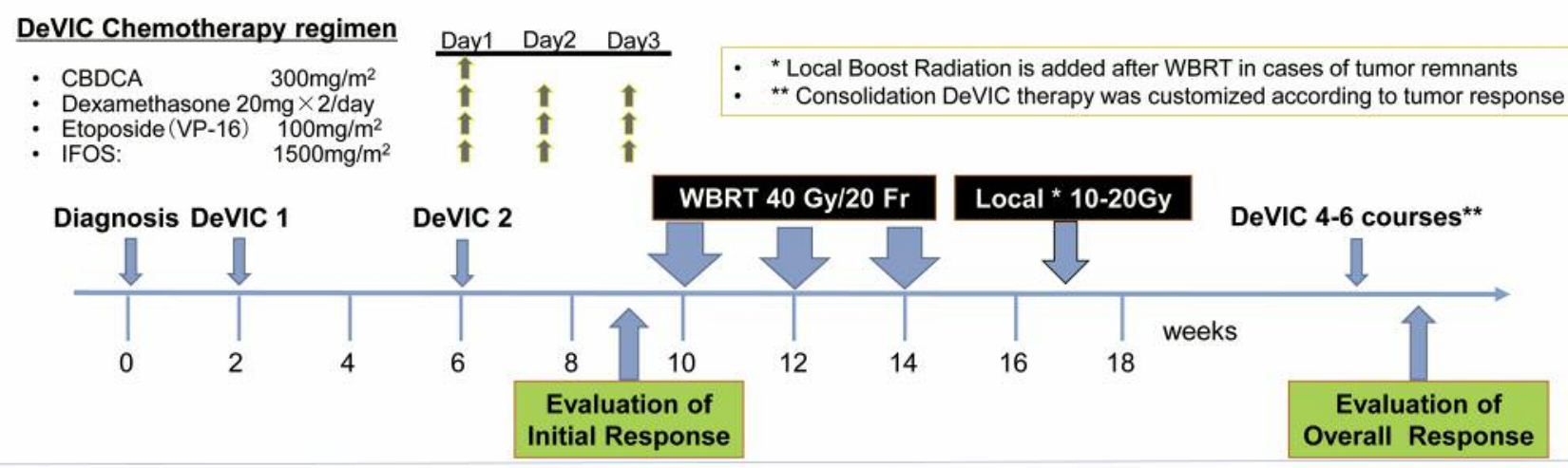

\section{HD-MTX chemotherapy regimen}

MTX $3.5 \mathrm{~g} / \mathrm{m}^{2}$ every two weeks

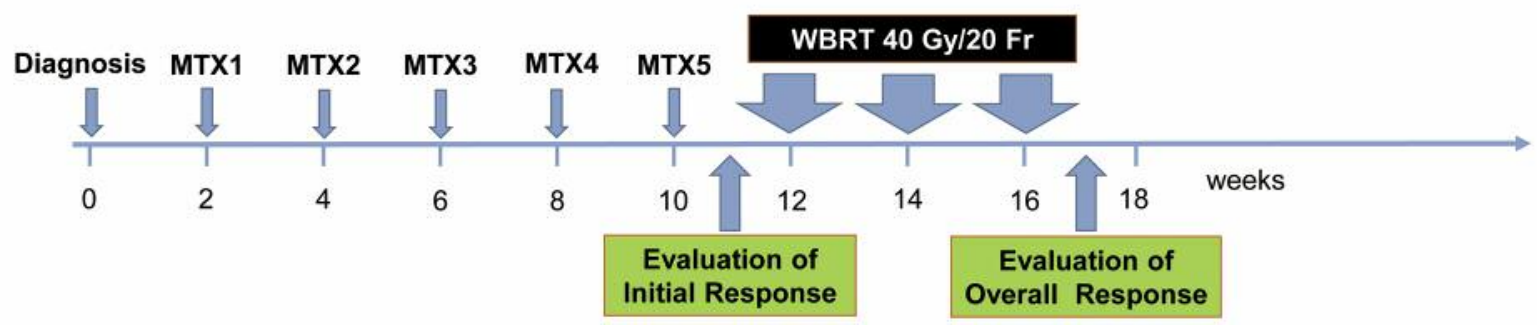

Figure 1. Schema of DeVIC and HD-MTX chemotherapy protocol. The timing of the evaluation of initial and overall responses was shown in these regimens.
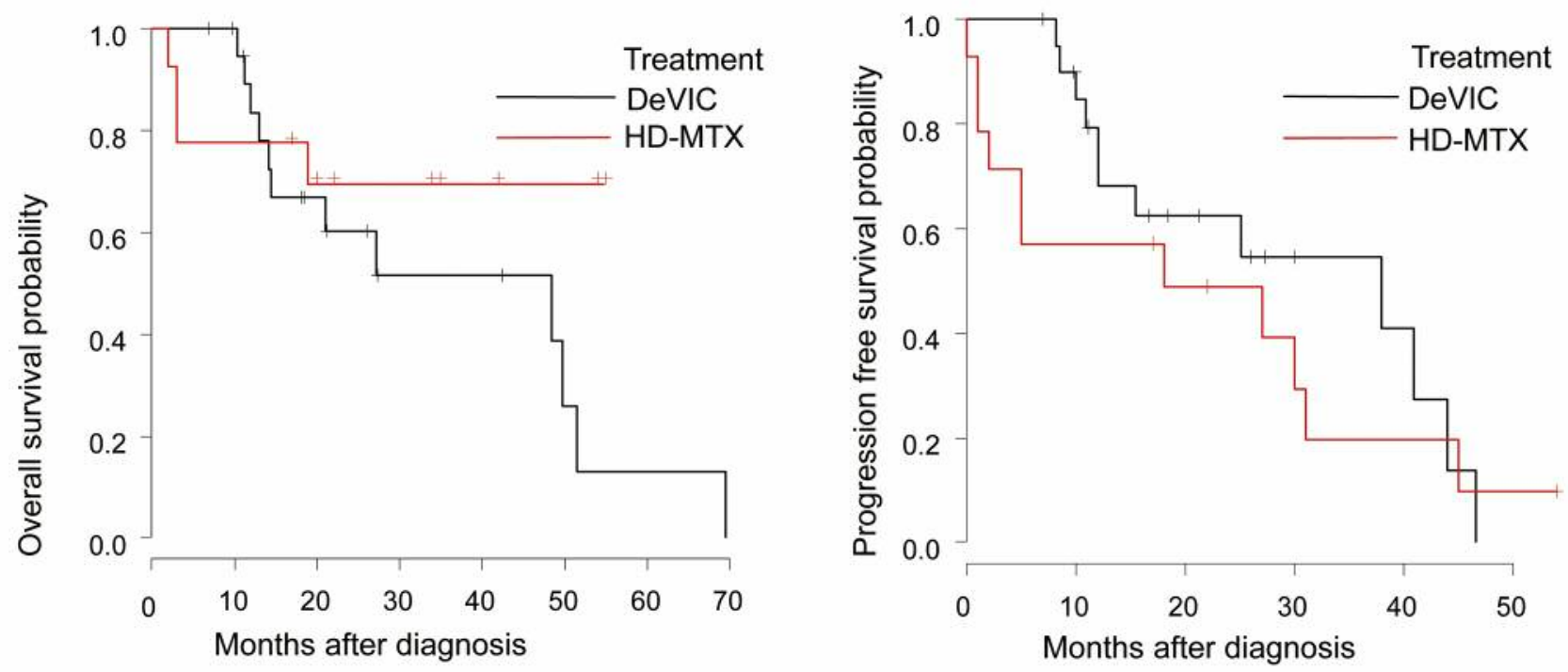

Figure 2. Kaplan-Meier curves showing overall survival (OS) and progression-free survival (PFS) for the patients treated with DeVIC therapy and HD-MTX monotherapy, respectively.

Adverse events for DeVIC and HD-MTX chemotherapy. Severe adverse events of grades 3 and 4 that were related to the two chemotherapy regimens were compared. Grade 3 or more severe neutropenia was observed in $76.2 \%$ and $7.1 \%$ patients of the DeVIC and HD-MTX cohorts, respectively. Febrile neutropenia with infection was observed in $9.5 \%$ 
Table III. 12 and 24 month survival data for DeVIC and HD-MTX treatment.

\begin{tabular}{lcc}
\hline (Months) & DeVIC & HD-MTX \\
\hline 12M-OS (\%) & 83.6 & 78.6 \\
24M-OS (\%) & 60.2 & 61.1 \\
12M-PFS (\%) & 68.1 & 61.5 \\
24M-PFS (\%) & 62.4 & 55.6 \\
\hline
\end{tabular}

OS: Overall survival; PFS: progression-free survival; DeVIC: dexamethasone, etoposide, ifosfamide and carboplatin; HD-MTX: Highdose methotrexate.

patients of the DeVIC cohort, but was not observed in the HD-MTX cohort. The toxicities associated with grade 3 and grade 4 leukopenia, neutropenia, and thrombocytopenia were significantly higher in the DeVIC cohort than that in the HDMTX cohort ( $p=0.0001,0.0001$, and 0.0045 respectively); however, these toxicities were all clinically manageable. Furthermore, there were no treatment-related deaths in both cohorts.

Delayed neurotoxicity. Leukoencephalopathy of grade 3 or more was identified in $31.6 \%$ and $36.3 \%$ patients of the DeVIC and HD-MTX cohorts, respectively. All patients who had severe white matter changes, which were observed on MRI, developed dementia that was consistent with delayed neurotoxicity. All these patients also had cognitive deficits that affected their activities of daily life thus required care to various degrees. Mild or moderate cognitive deficits resulting in impairment of concentration, memory, and orientation were present in 2 patients in the DeVIC group and 4 patients in the HD-MTX group, at the end of the observation period. Two patients in the HD-MTX group were completely bedridden at the end of the observation period. Details of major grades 3 and 4 adverse events are shown in Table IV.

\section{Discussion}

Two different treatment regimens were administered to patients with newly-diagnosed PCNSL at the Nagoya University Hospital from 2002 to 2014: DeVIC therapy from 2002 to 2010, and HD-MTX therapy from 2010 to 2014. Although patient backgrounds differed among these study periods, the baseline characteristics of the patients were relatively similar in both cohorts. The number of senile patients of age 60 or above was significantly higher in the HD-MTX group; however, this group also contained significantly more patients with a good initial KPS score of
70 or above. Age and initial KPS scores are widely known as factors that influence the treatment outcomes in patients with PCNSL $(22,23)$. The patients in the HD-MTX cohort were generally elderly; however, had good initial KPS scores. While age is an important factor to be considered while choosing a treatment modality and can influence the overall outcomes, patients with PCNSL would almost always comprise an older population making an aggressive chemotherapy inevitable $(24,25)$. All patients in both treatment groups were immunocompetent, and had no other life-threatening conditions that may have otherwise influenced their survival.

In our study, DeVIC therapy resulted in very high response rates compared with HD-MTX therapy plus WBRT. Moreover, the one-year and two-year PFS rates were higher in the DeVIC cohort than in the HD-MTX cohort. Final PFS was longer in the DeVIC group than in the HD-MTX group, although the results failed to achieve a statistical significance. The tendency for a longer PFS may be the result of a better initial response to DeVIC therapy. Owing to the high response rates, the one-year OS rate was also marginally higher in the DeVIC cohort than in the HD-MTX cohort. Median OS for HD-MTX cohort was not reached to enable comparison with the median OS of 47.8 months in the DeVIC cohort. However, the outcomes of DeVIC therapy that we observed are comparable with other previously published outcomes of HD-MTX-based treatment $(8,9,13,18,26)$. These findings may indicate the potential efficacy of DeVIC chemotherapy for the treatment of patients with PCNSL.

Grade 3 and 4 adverse events showed greater association with DeVIC therapy than with HD-MTX-based therapy. It may be more challenging for patients with PCNSL with poor KPS scores to undergo DeVIC therapy than to undergo HDMTX therapy (24). The adverse events observed in both therapies were not associated with death or permanent morbidities. The results of late neurotoxicity in the patient groups undergoing the two treatment regimens are rather striking, with both exhibiting approximately $30 \%$ probability of eventually developing leukoencephalopathy. All patients in both cohorts underwent WBRT with 40 Gy of radiation or more. Radiation-induced leukoencephalopathy is a known side-effect of PCNSL treatment that typically includes WBRT (13). The use of WBRT with chemotherapy may increase the incidence of neurotoxicity further than that observed with chemotherapy alone (MTX monotherapy) (14, 26). The leukoencephalopathy incidence rate of $30 \%$ observed in our study is similar to its previously reported values; this further supports the notion that radiation-based leukoencephalopathy should be addressed as the next step in PCNSL treatment.

To the best of our knowledge, this is the first study to compare the results of HD-MTX chemotherapy with previously reported results of DeVIC chemotherapy for 
Table IV. Severe adverse events in DeVIC and HD-MTX chemotherapy.

\begin{tabular}{|c|c|c|c|c|c|c|c|c|}
\hline \multirow{3}{*}{ Adverse Events } & \multicolumn{4}{|c|}{ DeVIC } & \multicolumn{4}{|c|}{ HD-MTX } \\
\hline & \multicolumn{2}{|c|}{ Grade 3} & \multicolumn{2}{|c|}{ Grade 4} & \multicolumn{2}{|c|}{ Grade 3} & \multicolumn{2}{|c|}{ Grade 4} \\
\hline & No. & $\%$ & No. & $\%$ & No. & $\%$ & No. & $\%$ \\
\hline Leukopenia & 2 & 9.5 & 14 & 66.7 & 1 & 7.1 & 0 & 0 \\
\hline Neutropenia & 1 & 4.8 & 15 & 71.4 & 0 & 0 & 1 & 7.1 \\
\hline Anemia & 7 & 33.3 & 0 & & 3 & 21.4 & 0 & 0 \\
\hline Thrombocytopenia & 5 & 23.8 & 4 & 19.0 & 0 & 0 & 0 & 0 \\
\hline Infection accompanied by grade 3 or 4 Neutropenia & 0 & 0 & 2 & 9.5 & 0 & 0 & 0 & 0 \\
\hline Appetite loss-Nausea & 2 & 9.5 & 0 & 0 & 0 & 0 & 1 & 7.1 \\
\hline Other GI Disorder & 0 & 0 & 0 & 0 & 0 & 0 & 0 & 0 \\
\hline Hyponatremia & 4 & 19.0 & 0 & 0 & 0 & 0 & 0 & 0 \\
\hline Hypokalemia & 2 & 9.5 & 0 & 0 & 0 & 0 & 0 & 0 \\
\hline Neurotoxicity & \multirow{2}{*}{\multicolumn{4}{|c|}{$6(31.6 \%)$}} & \multirow{2}{*}{\multicolumn{4}{|c|}{$4(36.3 \%)$}} \\
\hline Leukoencephalopathy & & & & & & & & \\
\hline
\end{tabular}

GI: Gastrointestinal; DeVIC: dexamethasone, etoposide, ifosfamide and carboplatin; HD-MTX: high-dose methotrexate.

PCNSL that was treated within the same institution. Previously reported series regarding the clinical outcomes of HD-MTX chemotherapy in PCNSL patients are shown in Table V. In addition, these data are shown along with those of the present DeVIC study (Table V). Comparing the outcomes of the DeVIC followed by the WBRT regimen with other published regimens for newly diagnosed PCNSL patients shows that DeVIC chemotherapy plays a significant role in clinical outcomes comparable to previously reported HD-MTX chemotherapy with WBRT.

However, our study has several limitations that should be mentioned. The major limitation of this study is that it is a retrospective study of regimens that were used for the treatment of patients with PCNSL at different times, and not a randomized parallel comparison study, and it has a small sample size study, especially in the HD-MTX chemotherapy with WBRT arm. Furthermore, another major limitation may be that our treatment with 5 cycles of HD-MTX might be considered substandard therapy. At present, HD-MTX is thought to be the most efficient known cytostatic drug for PCNSL, and its use may be the most important prognostic variable in relationship to the survival of patients with PCNSLs. However, the optimal dose and number of cycles of HD-MTX have not been defined. Batchelor et al. in the New Approaches to Brain Tumor Therapy (NABTT) 96-07 (4) demonstrated that HD-MTX alone produced a $74 \%$ response rate and median progression-free survival of 12.8 months. In that report, patients received methotrexate $8 \mathrm{~g} / \mathrm{m}^{2}$ until a complete response (CR) was achieved or a maximum of eight cycles was administered. Based on several previous reports $(4,5,7,13,27-29)$, systemic doses greater than 1.0 $\mathrm{mg} / \mathrm{m}^{2}$, especially $1.0-8.0 \mathrm{mg} / \mathrm{m}^{2}$ of methotrexate, have a clinical effect on PCNSL patients. In addition, as indicated, the evidence suggests that more than four cycles of MTX are mandatory to obtain an effective response (30); therefore, our HD-MTX arm regimen was scheduled to receive methotrexate $3.5 \mathrm{~g} / \mathrm{m} 2$ with five cycles of HD-MTX before WBRT. Although our regimen of MTX consists of a maximum of 5 cycles of MTX, which may not be universally considered the standard treatment with MTX alone, our results are comparable to those in the literature, including those with more than 5 cycles of HD-MTX therapy.

Another limitation is that the duration of the study was long; it is possible that characteristics of patients included in the study may vary across the periods of observation, and comparison among patients at different time periods may not be completely accurate. Furthermore, it was impossible to only compare the efficacy of the two chemotherapy regimens, DeVIC chemotherapy and HD-MTX monotherapy, because both chemotherapies were combined with WBRT, that contributed to the clinical outcome of PCNSL. While the effect of WBRT added to chemotherapy cannot be ignored, it should be noted that both the DeVIC and MTX cohorts had almost equal amounts of WBRT (nearly 40 Gy). However, as both these treatment regimens were used in the same institution with the same level of care, and in patients with similar characteristics, we believe that this contributes to the significance of our study as a comparison of the two regimens. Though HD-MTX therapy has become the standard regimen-of-treatment for PCNSL, there is still no alternative treatment in cases that are refractory to HD-MTX therapy. 
Table V. Studies that included HD-MTX based therapy and DeVIC chemotherapy for PCNSL.

\begin{tabular}{|c|c|c|c|c|c|}
\hline Study & $\begin{array}{l}\text { Patient } \\
\text { No. }\end{array}$ & $\begin{array}{l}\text { Median } \\
\text { age (years) }\end{array}$ & Regimen & $\begin{array}{l}\text { Median PFS } \\
\text { (months) }\end{array}$ & $\begin{array}{l}\text { Median OS } \\
\text { (months) }\end{array}$ \\
\hline Hiraga et al. (1999) (8) & 29 & 56.2 & MTX 100 mg/kg (2-3cycles) & 35.2 & 39.3 \\
\hline Bessell et al. (2002) (32) & 57 & 59 & $\begin{array}{l}\text { CHOD (CPA, VCR, DXR, and dexamethasone) } \\
\text { +BVAM (BCNU, VCR, and MTX: } 1.5 \mathrm{~g} / \mathrm{m}^{2} ; \\
\text { Ara-C) } 2 \times 42 \text {-day cycles, WBRT: } 45 \text { Gy or } 30.6 \mathrm{~Gy}\end{array}$ & NG & 40 \\
\hline $\begin{array}{l}\text { DeAngelis et al. } \\
\text { RTOG 93-10 (2002) (13) }\end{array}$ & 98 & 56.5 & $\begin{array}{l}\text { MTX: } 2.5 \mathrm{~g} / \mathrm{m}^{2}(5 \mathrm{cycles}), \text { IT-MTX, } \\
\text { procarbazine, VCR, Ara-C, WBRT }\end{array}$ & 24 & 36.9 \\
\hline $\begin{array}{l}\text { Poortmans } \text { et al. } \\
\text { EORTC phase II } 20962 \\
(2003)(27)\end{array}$ & 52 & 51 & $\begin{array}{c}\text { MTX } 3 \mathrm{~g} / \mathrm{m}^{2} \text { ( } 2 \text { cycles), teniposide; carmustine; } \\
\text { methylprednisolone; IT-MTX; cytarabine; } \\
\text { hydrocortisone; WBRT } 40 \mathrm{~Gy}\end{array}$ & NG & 46 \\
\hline $\begin{array}{l}\text { Batchelor } \text { et al. NABTT } \\
\text { 96-07 (2003) (4) }\end{array}$ & 25 & 60 & $\begin{array}{c}\text { MTX } 8 \mathrm{~g} / \mathrm{m}^{2} \text { (until CR was achieved or } \\
\text { maximum of } 8 \text { cycles) }\end{array}$ & 12.8 & NR \\
\hline $\begin{array}{l}\text { Abrey et al. (2006) (23) } \\
\text { O'Brien et al. }\end{array}$ & 338 & 61 & MTX-based regimen + WBRT & NG & 37 \\
\hline $\begin{array}{l}\text { Trans-Tasman Radiation } \\
\text { Oncology Group (2006) (7) }\end{array}$ & 46 & 58 & MTX $1 \mathrm{~g} / \mathrm{m}^{2}$ ( 2 cycles $)+$ WBRT 45-50.4 Gy & NG & 36 \\
\hline Ferreri et al. (2009) & 40 & 58 & MTX $3.5 \mathrm{~g} / \mathrm{m}^{2}$ (4 cycles) + WBRT 36-40 Gy (+9Gy boost) & 3 years $21 \%$ & 3 years $32 \%$ \\
\hline (28) & 39 & 59 & $\begin{array}{l}\text { MTX } 3.5 \mathrm{~g} / \mathrm{m}^{2}+\text { Ara-C } 2 \mathrm{~g} / \mathrm{m}^{2} \text { twice per day } \\
\text { on d } 2-3(4 \text { cycles })+36-40 \text { Gy (+9Gy boost })\end{array}$ & & \\
\hline Thiel et al. & 551 & 63 & MTX $4 \mathrm{~g} / \mathrm{m}^{2}$ (6 cycles $)+$ WBRT $45 \mathrm{~Gy}$ & 18.3 & 32.4 \\
\hline G-PCNSL-SG-1 (2010) (5) & & & MTX:4 $\mathrm{g} / \mathrm{m}^{2}$ (6 cycles) + ifosfamide & 11.9 & 37.1 \\
\hline Wieduwilt et al. (2012) (29) & 31 & 61 & $\begin{array}{l}\left.\text { MTX } 8 \mathrm{~g} / \mathrm{m}^{2} \text { ( } 8 \text { cycles }\right) \text {, rituximab, } \\
\text { temozolomide, etoposide, cytarabine }\end{array}$ & 24 & 66 \\
\hline Current study & 21 & 60.5 & DeVIC + WBRT: 40Gy & 37.4 & 47.8 \\
\hline & 14 & 67 & MTX: $3.5 \mathrm{~g} / \mathrm{m}^{2}$ (5 cycles) +WBRT 40Gy & 25.3 & NR \\
\hline
\end{tabular}

PCNSL: Primary central nervous system lymphoma; RTOG: radiation therapy oncology group; EORTC: European Organization for Research and Treatment of Cancer; DeVIC: dexamethasone, etoposide, ifosfamide, and carboplatin; HD-MTX: high-dose methotrexate; WBRT: whole-brain radiation therapy; CPA: cyclophosphamide; VCR: vincristine; DXR: doxorubicin; BCNU: 1,3-bis(2-chloroethyl)-1-nitrosourea; ORR: overall response rate; PFS: progression-free survival; OS: overall survival; MTX: methotrexate; IT-MTX: intrathecal methotrexate; NG: not given; NR: not reached.

DeVIC therapy has higher early response rates, longer PFS, and manageable adverse events, and may potentially be a candidate to treat cases that are refractory to MTX-based therapy. In fact, we have previously reported the efficacy of DeVIC in recurrent or refractory PCNSL (31). This study showed that DeVIC chemotherapy yielded high response rates of CR and PR (83.3\%) for recurrent PCNSL (31). Treatment regimens with high response rates are associated with better outcomes in patients with malignancies that are not responsive to standard treatment regimens. Treatments with high response rates may also rapidly improve the quality-of-life of patients with recurrent malignancies. Thus, DeVIC therapy could become a feasible and active therapeutic option for patients with PCNSL relapsed or refractory to HD-MTX-based chemotherapy.

In conclusion, this retrospective clinical study has shown that the outcomes associated with DeVIC therapy are comparable to those associated with HD-MTX monotherapy plus WBRT, for newly diagnosed PCNSL. In spite of the small sample size and the retrospective nature of this study, we believe that our study may provide a basis for future prospective studies on comparison of DeVIC chemotherapy with HD-MTX monotherapy plus WBRT for patients with PCNSL. Therefore, we are planning a prospective randomized control trial to evaluate the clinical outcomes of DeVIC chemotherapy followed by WBRT in patients with PCNSL relapsed or refractory to HD-MTXbased chemotherapy.

\section{Conflicts of Interest}

The Authors declare that they have no conflicts of interest.

\section{References}

1 Nelson DF, Martz KL, Bonner H, Nelson JS, Newall J, Kerman HD, Thomson JW and Murray KJ: Non-Hodgkin's lymphoma of the brain: can high dose, large volume radiation therapy improve survival? Report on a prospective trial by the Radiation Therapy Oncology Group (RTOG): RTOG 8315. Int J Radiat Oncol Biol Phys 23: 9-17, 1992. 
2 Pels H, Schmidt-Wolf IG, Glasmacher A, Schulz H, Engert A, Diehl V, Zellner A, Schackert G, Reichmann H, Kroschinsky F, Vogt-Schaden M, Egerer G, Bode U, Schaller C, Deckert M, Fimmers R, Helmstaedter C, Atasoy A, Klockgether T and Schlegel U: Primary central nervous system lymphoma: results of a pilot and phase II study of systemic and intraventricular chemotherapy with deferred radiotherapy. J Clin Oncol 21: 4489-4495, 2003.

3 Yang SH, Lee KS, Kim IS, Hong JT, Sung JH, Son BC, Lee SW and Hong YK: Long-term survival in primary CNS lymphoma treated by high-dose methotrexate monochemotherapy: role of STAT6 activation as prognostic determinant. J Neurooncol 92: 65-71, 2009.

4 Batchelor T, Carson K, O’ Neill A, Grossman SA, Alavi J, New $\mathrm{P}$, Hochberg $\mathrm{F}$ and Priet R: Treatment of primary CNS lymphoma with methotrexate and deferred radiotherapy: a report of NABTT 96-07. J Clin Oncol 21: 1044-1049, 2003.

5 Thiel E, Korfel A, Martus P, Kanz L, Griesinger F, Rauch M, Roth A, Hertenstein B, von Toll T, Hundsberger T, Mergenthaler HG, Leithauser M, Birnbaum T, Fischer L, Jahnke K, Herrlinger U, Plasswilm L, Nagele T, Pietsch T, Bamberg M and Weller M: High-dose methotrexate with or without whole brain radiotherapy for primary CNS lymphoma (G-PCNSL-SG-1): a phase 3, randomised, non-inferiority trial. Lancet Oncol 11: 1036-1047, 2010.

6 Gerstner ER, Carson KA, Grossman SA and Batchelor TT: Longterm outcome in PCNSL patients treated with high-dose methotrexate and deferred radiation. Neurology 70: 401-402, 2008.

7 O'Brien PC, Roos DE, Pratt G, Liew KH, Barton MB, Poulsen MG, Olver IN, Trotter GE and Trans-Tasman Radiation Oncology G: Combined-modality therapy for primary central nervous system lymphoma: long-term data from a Phase II multicenter study (Trans-Tasman Radiation Oncology Group). Int J Radiat Oncol Biol Phys 64: 408-413, 2006.

8 Hiraga S, Arita N, Ohnishi T, Kohmura E, Yamamoto K, Oku Y, Taki T, Sato M, Aozasa K and Yoshimine T: Rapid infusion of high-dose methotrexate resulting in enhanced penetration into cerebrospinal fluid and intensified tumor response in primary central nervous system lymphomas. J Neurosurg 91: 221-230, 1999.

9 O’Brien P, Roos D, Pratt G, Liew K, Barton M, Poulsen M, Olver I and Trotter G: Phase II multicenter study of brief singleagent methotrexate followed by irradiation in primary CNS lymphoma. J Clin Oncol 18: 519-526, 2000.

10 DeAngelis LM, Yahalom J, Thaler HT and Kher U: Combined modality therapy for primary CNS lymphoma. J Clin Oncol 10: 635-643, 1992.

11 Shah GD, Yahalom J, Correa DD, Lai RK, Raizer JJ, Schiff D, LaRocca R, Grant B, DeAngelis LM and Abrey LE: Combined immunochemotherapy with reduced whole-brain radiotherapy for newly diagnosed primary CNS lymphoma. J Clin Oncol 25: 4730-4735, 2007.

12 Linnebank M, Pels H, Kleczar N, Farmand S, Fliessbach K, Urbach H, Orlopp K, Klockgether T, Schmidt-Wolf IG and Schlegel U: MTX-induced white matter changes are associated with polymorphisms of methionine metabolism. Neurology 64 : 912-913, 2005.

13 DeAngelis LM, Seiferheld W, Schold SC, Fisher B, Schultz CJ and Radiation Therapy Oncology Group S: Combination chemotherapy and radiotherapy for primary central nervous system lymphoma: Radiation Therapy Oncology Group Study 93-10. J Clin Oncol 20: 4643-4648, 2002.

14 Zacher J, Kasenda B, Engert A and Skoetz N: The role of additional radiotherapy for primary central nervous system lymphoma. Cochrane Database Syst Rev: CD009211, 2014.

15 Rubenstein JL, Hsi ED, Johnson JL, Jung SH, Nakashima MO, Grant B, Cheson BD and Kaplan LD: Intensive chemotherapy and immunotherapy in patients with newly diagnosed primary CNS lymphoma: CALGB 50202 (Alliance 50202). J Clin Oncol 31: 3061-3068, 2013.

16 Morris PG, Correa DD, Yahalom J, Raizer JJ, Schiff D, Grant B, Grimm S, Lai RK, Reiner AS, Panageas K, Karimi S, Curry R, Shah G, Abrey LE, DeAngelis LM and Omuro A: Rituximab, methotrexate, procarbazine, and vincristine followed by consolidation reduced-dose whole-brain radiotherapy and cytarabine in newly diagnosed primary CNS lymphoma: final results and long-term outcome. J Clin Oncol 31: 3971-3979, 2013.

17 Omuro A, Correa DD, DeAngelis LM, Moskowitz CH, Matasar MJ, Kaley TJ, Gavrilovic IT, Nolan C, Pentsova E, Grommes CC, Panageas KS, Baser RE, Faivre G, Abrey LE and Sauter CS: R-MPV followed by high-dose chemotherapy with TBC and autologous stem-cell transplant for newly diagnosed primary CNS lymphoma. Blood 125: 1403-1410, 2015.

18 Motomura K, Natsume A, Fujii M, Ito M, Momota H and Wakabayashi T: Long-term survival in patients with newly diagnosed primary central nervous system lymphoma treated with dexamethasone, etoposide, ifosfamide and carboplatin chemotherapy and whole-brain radiation therapy. Leuk Lymphoma 52: 2069-2075, 2011.

19 Louis DN, Ohgaki H, Wiestler OD, Cavenee WK, Burger PC, Jouvet A, Scheithauer BW and Kleihues P: The 2007 WHO classification of tumours of the central nervous system. Acta Neuropathol 114: 97-109, 2007.

20 Abrey LE, Batchelor TT, Ferreri AJ, Gospodarowicz M, Pulczynski EJ, Zucca E, Smith JR, Korfel A, Soussain C, DeAngelis LM, Neuwelt EA, O'Neill BP, Thiel E, Shenkier T, Graus F, van den Bent M, Seymour JF, Poortmans P, Armitage JO, Cavalli F, and International Primary CNSLCG: Report of an international workshop to standardize baseline evaluation and response criteria for primary CNS lymphoma. J Clin Oncol 23: 5034-5043, 2005.

21 Institute NC: Common terminology criteria for adverse events v4.0 In Edition 2009. 2009.

22 Hoang-Xuan K, Bessell E, Bromberg J, Hottinger AF, Preusser M, Ruda R, Schlegel U, Siegal T, Soussain C, Abacioglu U, Cassoux N, Deckert M, Dirven CM, Ferreri AJ, Graus F, Henriksson R, Herrlinger U, Taphoorn M, Soffietti R, Weller M, and European Association for Neuro-Oncology Task Force on Primary CNSL: Diagnosis and treatment of primary CNS lymphoma in immunocompetent patients: guidelines from the European Association for Neuro-Oncology. Lancet Oncol 16: e322-332, 2015.

23 Abrey LE, Ben-Porat L, Panageas KS, Yahalom J, Berkey B, Curran W, Schultz C, Leibel S, Nelson D, Mehta M and DeAngelis LM: Primary central nervous system lymphoma: the Memorial Sloan-Kettering Cancer Center prognostic model. J Clin Oncol 24: 5711-5715, 2006.

24 Villano JL, Koshy M, Shaikh H, Dolecek TA and McCarthy BJ: Age, gender, and racial differences in incidence and survival in primary CNS lymphoma. Br J Cancer 105: 1414-1418, 2011. 
25 Kasenda B, Ferreri AJ, Marturano E, Forst D, Bromberg J, Ghesquieres H, Ferlay C, Blay JY, Hoang-Xuan K, Pulczynski EJ, Fossa A, Okoshi Y, Chiba S, Fritsch K, Omuro A, O'Neill BP, Bairey O, Schandelmaier S, Gloy V, Bhatnagar N, Haug S, Rahner S, Batchelor TT, Illerhaus G and Briel M: First-line treatment and outcome of elderly patients with primary central nervous system lymphoma (PCNSL) - a systematic review and individual patient data meta-analysis. Ann Oncol 26: 1305-1313, 2015.

26 Gavrilovic IT, Hormigo A, Yahalom J, DeAngelis LM and Abrey LE: Long-term follow-up of high-dose methotrexate-based therapy with and without whole brain irradiation for newly diagnosed primary CNS lymphoma. J Clin Oncol 24: 4570-4574, 2006.

27 Poortmans PM, Kluin-Nelemans HC, Haaxma-Reiche H, Van't Veer M, Hansen M, Soubeyran P, Taphoorn M, Thomas J, Van den Bent M, Fickers M, Van Imhoff G, Rozewicz C, Teodorovic I, van Glabbeke M, European Organization for R, and Treatment of Cancer Lymphoma G: High-dose methotrexate-based chemotherapy followed by consolidating radiotherapy in nonAIDS-related primary central nervous system lymphoma: European Organization for Research and Treatment of Cancer Lymphoma Group Phase II Trial 20962. J Clin Oncol 21: 44834488, 2003.

28 Ferreri AJ, Reni M, Foppoli M, Martelli M, Pangalis GA, Frezzato M, Cabras MG, Fabbri A, Corazzelli G, Ilariucci F, Rossi G, Soffietti R, Stelitano C, Vallisa D, Zaja F, Zoppegno L, Aondio GM, Avvisati G, Balzarotti M, Brandes AA, Fajardo J, Gomez H, Guarini A, Pinotti G, Rigacci L, Uhlmann C, Picozzi P, Vezzulli P, Ponzoni M, Zucca E, Caligaris-Cappio F, Cavalli F, and International Extranodal Lymphoma Study G: High-dose cytarabine plus high-dose methotrexate versus high-dose methotrexate alone in patients with primary CNS lymphoma: a randomised phase 2 trial. Lancet 374: 1512-1520, 2009.
29 Wieduwilt MJ, Valles F, Issa S, Behler CM, Hwang J, McDermott M, Treseler P, O'Brien J, Shuman MA, Cha S, Damon LE and Rubenstein JL: Immunochemotherapy with intensive consolidation for primary CNS lymphoma: a pilot study and prognostic assessment by diffusion-weighted MRI. Clin Cancer Res 18: 1146-1155, 2012.

30 Abrey LE, Moskowitz CH, Mason WP, Crump M, Stewart D, Forsyth P, Paleologos N, Correa DD, Anderson ND, Caron D, Zelenetz A, Nimer SD and DeAngelis LM: Intensive methotrexate and cytarabine followed by high-dose chemotherapy with autologous stem-cell rescue in patients with newly diagnosed primary CNS lymphoma: an intent-to-treat analysis. J Clin Oncol 21: 4151-4156, 2003.

31 Takasu S, Wakabayashi T, Kajita Y, Hatano N, Hatano H, Usui $\mathrm{T}$, Kinoshita $\mathrm{T}$ and Yoshida J: [Effectiveness of DeVIC chemotherapy for recurrent primary central nervous system lymphoma]. No Shinkei Geka 28: 789-794, 2000.

32 Bessell EM, Lopez-Guillermo A, Villa S, Verger E, Nomdedeu B, Petit J, Byrne P, Montserrat E and Graus F: Importance of radiotherapy in the outcome of patients with primary CNS lymphoma: an analysis of the CHOD/BVAM regimen followed by two different radiotherapy treatments. J Clin Oncol 20: 231236, 2002. 